\title{
DEVELOPMENT OF REAL-TIME REMOTE SAFETY MANAGEMENT SYSTEM FOR STRUCTURES USING INTERNET AND IoT SENSOR
}

\author{
Chang Jin Yang \\ Professor, Department of Architectural \& Civil Engineering, Dong-seo \\ University, Korean \\ cjyang@dongseo.ac.kr
}

\begin{abstract}
Recently, the construction industry is paying attention to the permanent safety management of the structures. However, most structural safety diagnosis management methods are managed by manual measurement method, in which technicians measure the displacement of facility on a regular basis. Since the technician must be put in every time measurement is required, there is a limit in confirming the displacement of the structure in advance and responding immediately. Therefore, the necessity of the always-on safety monitoring system for structure safety management is emerging. In addition, it is important to ensure the reliability of the management personnel by systematicizing and standardizing the measurement management method for securing the safety of structures. Therefore, the purpose of this study is to secure the technological competitiveness by developing IoT sensor network based system using wireless communication infrastructure and develop integrated safety management system by adding various sensors. Through this study, we will build a smart structural safety management system that acquires and utilizes fast measurement data for structural deformation.
\end{abstract}

Keywords - wireless, safety monitoring system, IoT sensor, real-time remote, smart structural

\section{INTRODUCTION}

\subsection{STATUS OF MEASUREMENT MANAGEMENT ON STRUCTURES}

Although much effort is currently being made to recognize the importance of safety management of structures around the world, structural areas that have the greatest impact on the safety of structures are those that require a high level of expertise and are judged by experts on-site diagnosis [1]. However, the number of experts is absolutely lacking compared to the subject matter to be managed, and we are coping with structural problems after they occur, so we have limitations in preventing accidents. To improve this, a monitoring system should be developed to monitor the damage status of the structure at all times and installed on-site to provide expert-level programs and management systems to detect and determine abnormal conditions of the structure in advance so that the basis for safety management can be established to prevent accidents in advance [2].

In addition, in the construction industry, the application of information technology (IT) such as a web-based database, wireless communication, mobile devices, etc. is expanding. However, the use of IT is limited in the practical application of construction

Received: November 11, 2019

Reviewed: January 24, 2020

Accepted: February 3, 2020

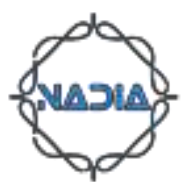


work and does not contribute directly to the improvement of quality and productivity in the convergence with the construction method [3]. On the other hand, the measurement management of structures has difficulties in accurately and promptly transfering information, and there are problems such as human injury, economic burden like recovery costs, and civil complaints, when an accident occurs. As shown in Figure 1, construction of a structure may cause damage to adjacent facilities along with subsidence of the ground, and in such a case, a large safety accident may result in personal injury [5]-[7].

In order to solve these problems, we will build a real-time remote measurement management system incorporating information technology such as internet and sensor technology when constructing structures [8]. Through this, it is expected to improve the stability of the structure, reduce the management cost of the construction project, improve the efficiency of the structure manager's maintenance, and establish the structure's preliminary safety system.
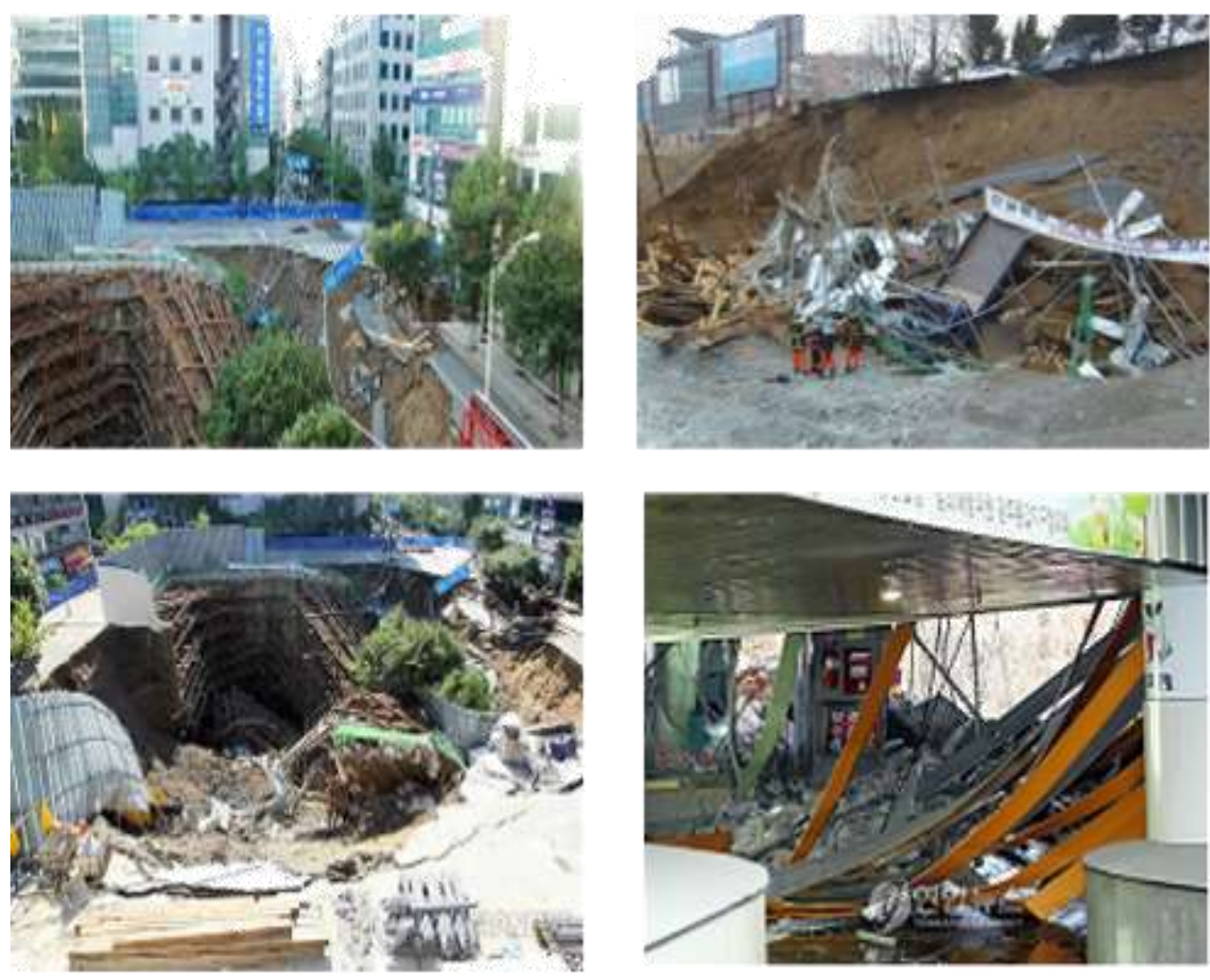

Fig. 1 Structures collapse example

\section{REVIEW OF DOMESTIC AND FOREIGN RELATED TECHNOLOGIES}

\subsection{DOMESTIC (SOUTH KOREA) TECHNOLOGY STATUS}

In accordance with the Special Law on Facility Maintenance, for type 1 facility, it was required to conduct a safety inspection twice a year and once every two years for precision inspection. In the case of safety management by measurement, most data are acquired by manual measurement method in the field, and the analysis of measured data during measurement is judged by the relevant experts, then the result is notified to the manager to take action [9]. In addition, most of the measuring equipment used in the field is expensive foreign imports. 


\subsection{FOREIGN TECHNOLOGY STATUS}

Foreign companies are divided into sensor manufacturers and specialized companies that manufacture and distribute each sensor element technology as a unit system.

These individual unit systems are composed of equipment that is standardized for the purpose of measurement, so that the technical requirements of users for the integrated management of the structure cannot be actively applied. In addition, most of the communication methods, which are data transmission systems, have a wired method, and thus have problems in installation and maintenance of the device [10]. In developed countries, foreign countries are developing and focusing on the field of structure maintenance using ubiquitous technology as shown in Table I. It is a system that detects displacement and transmits data by installing RFID tag in buildings or structures.

Table I. Domestic and overseas measurement technology

\begin{tabular}{|c|c|}
\hline Item & Contents \\
\hline Measurement & $\begin{array}{r}\text { In tunnel construction, real-time monitoring is performed by performing } \\
\text { automatic measurement throughout the structure. } \\
\text { Temporary measurement is performed manually at the same level as in } \\
\text { Korea. }\end{array}$ \\
\hline Safety diagnosis & $\begin{array}{r}\text { Establishment of Objective Evaluation System } \\
\text { Development and application of quantitative evaluation techniques }\end{array}$ \\
\hline $\begin{array}{c}\text { Integrated } \\
\text { Maintenance }\end{array}$ & $\begin{array}{r}\text { System is under development } \\
\text { Measuring } \\
\text { equipment }\end{array}$ \\
\hline
\end{tabular}

\section{DEVELOPMENT OF STRUCTURE SAFETY MANAGEMENT MEASUREMENT SYSTEM}

\subsection{SYSTEM CONFIGURATION}

There are global monitoring techniques and local monitoring techniques that measure changes in the structure's dynamic behavior using sensors such as accelerometers, speedometers, displacement meters, stress meters, ground reaction systems, and wind vanes. Local monitoring and management systems are divided into monitoring and maintenance systems for the stability of each structure, such as the columns that make up the structure. In the structural design phase, material properties and analytical model inevitably include significant errors from actual structural behavior [11]. Therefore, analysis and evaluation techniques based on measurement data are required. Based on this analysis and evaluation technology, alarm and maintenance systems for each structural level can be built. This allows programming of structural analysis techniques, on-site measurement data analysis techniques, comparative results of analysis results and measurement results.

The simplest way to determine the safety status by comparing and analyzing the measurement results is to make a judgment according to relevant standards. In an operational management system, a monitoring program is developed to store the values measured by the sensors and allow the user to check the measured data in real time according to established criteria [12]. The user can set the management value for each level required step by step, and the program is delivered to the user step by step when detecting data exceeding the management value set by the user. Therefore, the most 
important safety evaluation algorithm is developed and applied to the operation management system to inform the user of the status of the current structure.

\subsection{REMOTE MEASUREMENT SYSTEM}

The remote measurement system is capable of remotely monitoring the status information of remote structures through sensors and remote measuring devices installed in the field, and prevents accidents by automatically generating an alarm to the manager in case of an abnormality of the structure [13]. It is a system that not only saves time and expense through automated measurement management but also achieves scientificization of measurement management using analytical functions linked to experts. Table II compares wired and wireless remote measurement systems by applying the same type, quantity, and installation location of measuring sensors, and changing the rest of the system configuration and functions.

Table II. Telemetry System Comparison

\begin{tabular}{|c|c|c|c|}
\hline division & $\begin{array}{c}\text { Wired + Wireless } \\
\text { LAN }\end{array}$ & wireless & Remarks \\
\hline $\begin{array}{l}\text { Short construction } \\
\text { period and easy } \\
\text { facility management }\end{array}$ & $\begin{array}{l}\text { - Takes long } \\
\text { construction time } \\
\text { - Difficulty in facility } \\
\text { management due to } \\
\text { cable installation }\end{array}$ & $\begin{array}{l}\text { - Construction time is } \\
\text { shorter than wired. } \\
\text { - Easy maintenance } \\
\text { due to no } \\
\text { communication cable }\end{array}$ & $\begin{array}{l}\text { - No communication } \\
\text { cable construction }\end{array}$ \\
\hline $\begin{array}{c}\text { System } \\
\text { maintenance }\end{array}$ & $\begin{array}{l}\text {-All related sensors } \\
\text { are inoperable when } \\
\text { datalog error occurs } \\
\text { (up to 32) } \\
\text { - Maintenance } \\
\text { difficulty in case of } \\
\text { failure by imported } \\
\text { equipment }\end{array}$ & $\begin{array}{l}\text { - Only one related } \\
\text { sensor is inoperable } \\
\text { when datalog error } \\
\text { occurs } \\
\text { - Immediately } \\
\text { replace equipment in } \\
\text { case of failure }\end{array}$ & $\begin{array}{l}\text { - Easy repair and } \\
\text { replacement of } \\
\text { equipment }\end{array}$ \\
\hline $\begin{array}{l}\text { Alarm function and } \\
\text { expert input on site }\end{array}$ & $\begin{array}{l}\text { - Only checked in the } \\
\text { control room } \\
\text { - Expert input takes } \\
\text { time when problem } \\
\text { occurs }\end{array}$ & $\begin{array}{l}\text { - Alarm notification } \\
\text { and real-time } \\
\text { measurement mode } \\
\text { support for all } \\
\text { relevant parties } \\
\text { - Expert on-site input } \\
\text { immediately }\end{array}$ & $\begin{array}{l}\text { - } 24 \text { hour unmanned } \\
\text { surveillance analysis } \\
\text { expert support }\end{array}$ \\
\hline Technical services & $\begin{array}{l}\text {-Management starts } \\
\text { after completion of } \\
\text { construction } \\
\text { - No professional } \\
\text { always-on functions }\end{array}$ & $\begin{array}{l}\text { - Manageable during } \\
\text { construction } \\
\text {-Expert remote } \\
\text { management all the } \\
\text { time }\end{array}$ & - Battery operated \\
\hline Cost & $\begin{array}{l}\text {-High price } \\
\text { - Increasing cost at } \\
\text { scale }\end{array}$ & $\begin{array}{l}\text { - Relative low cost } \\
\text { - Reduced cost at } \\
\text { scale }\end{array}$ & $\begin{array}{l}\text { - Short construction } \\
\text { period and easy } \\
\text { maintenance }\end{array}$ \\
\hline
\end{tabular}

\subsection{DEVELOPMENT OF SHORT-RANGE AND LONG-RANGE WIRELESS REMOTE MEASURING DEVICE WITH INTEGRATED DATA LOGGER FUNCTION AND COMMUNICATION FUNCTION}

Conventional data processing methods have used data loggers (usually using 18 or 36 channels as data processing devices) connected to sensors to measure data. It is a method of transmitting data to a management server using portable data storage devices, wired 
and wireless communication devices. Since the data logger, communication device and management server are composed of one unit, it is a system that needs AC power to process data logger and communication device measured data at multiple points. Therefore, the bulk of the data processing unit and the need for a power cable and a management server caused a large initial cost, which was uneconomical [14].

This development technology, first, simplifies the system configuration by integrating the data logger function and communication function and secondly, it plans to develop short-range wireless remote device with a free communication charge and long-range wireless remote device with a communication fee. Construction feasibility can be secured by simplifying the system configuration, and economic feasibility can be secured by rationally deploying short-range and long-range wireless remote devices. Therefore, there is a need to develop a real-time remote safety management sensor suitable for system efficiency and economy [15].

\section{REAL-TIME REMOTE SAFETY SYSTEM USING INTERNET \& IoT SENSOR}

\subsection{SCOPE OF TECHNOLOGY APPLICATION}

By connecting various sensors such as inclinometer used in the structure, it is possible to implement the real-time wireless remote safety management monitoring system function applicable to various sensors and structures, which is excellent in applicability and expandability [16]. It is also a technology that can be used for the safety management of various facilities as well as structures. Various sensors such as strainer, load meter, displacement meter, water level meter, wind direction subtractor, rainfall meter, and accelerometer can be connected and applied to automatic measurement of various structures (dams, sides, tunnels, bridges, etc.) and permanent maintenance measurement such as fig 2 .

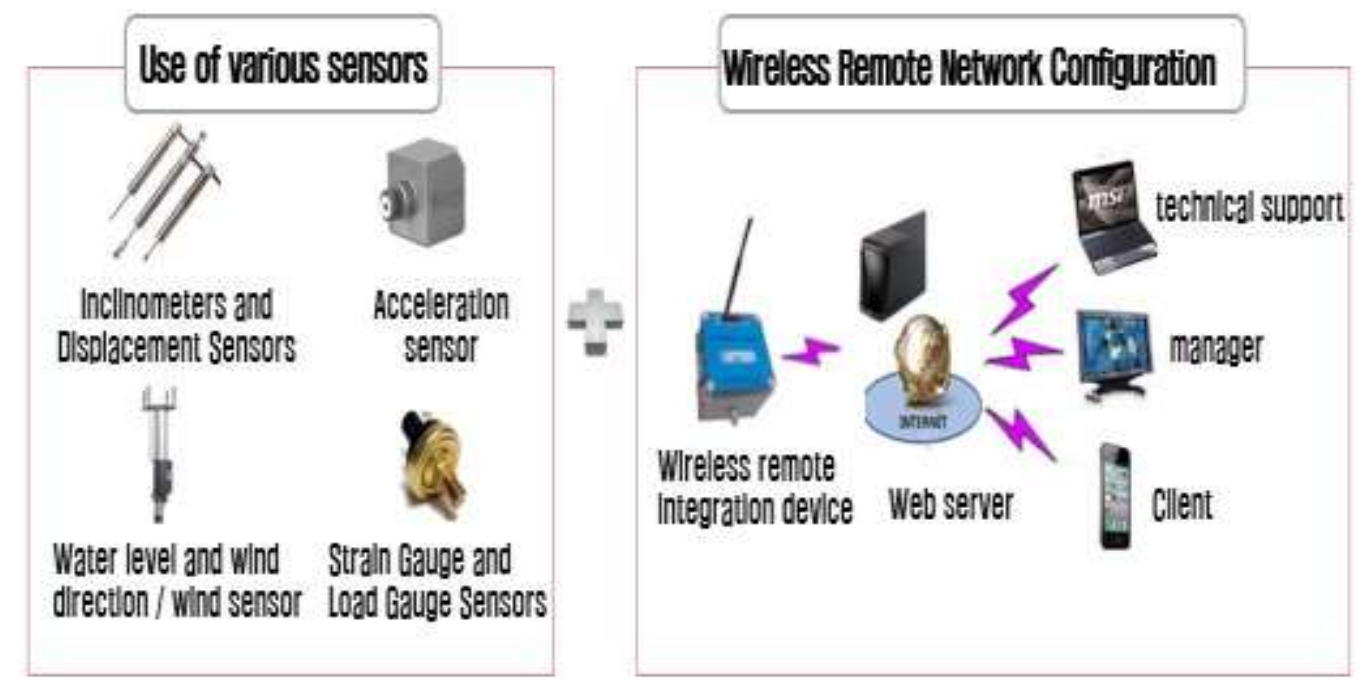

Fig. 2 Real-time wireless remote safety management monitoring system function applicable to various sensors and structures

\subsection{COMPOSITION OF THE PROGRAM}

4.2.1. NETWORK CONFIGURATION USING THE WIRELESS REMOTE MEASURING DEVICE: the real-time wireless telemetry device can automatically measure the data of the ubiquitous sensor installed in the seismic reinforcement structure 
and transmit the measured data to the subordinate computer at the remote location by using the wireless network. As shown in fig 3-4, a wireless telemetry system consists of a sensor, a wireless telemetry device, and a management program.

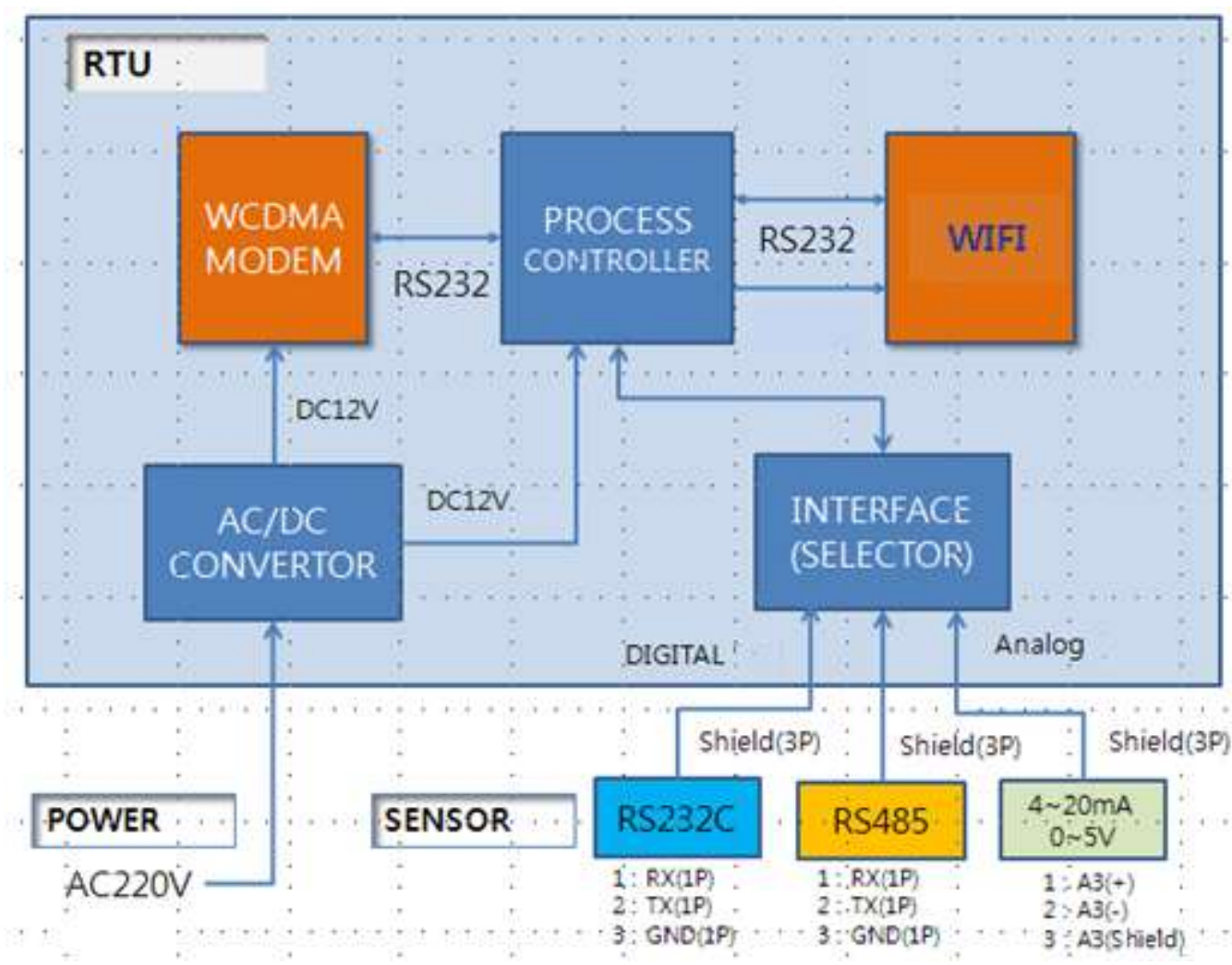

Fig. 3 Wireless remote measuring device

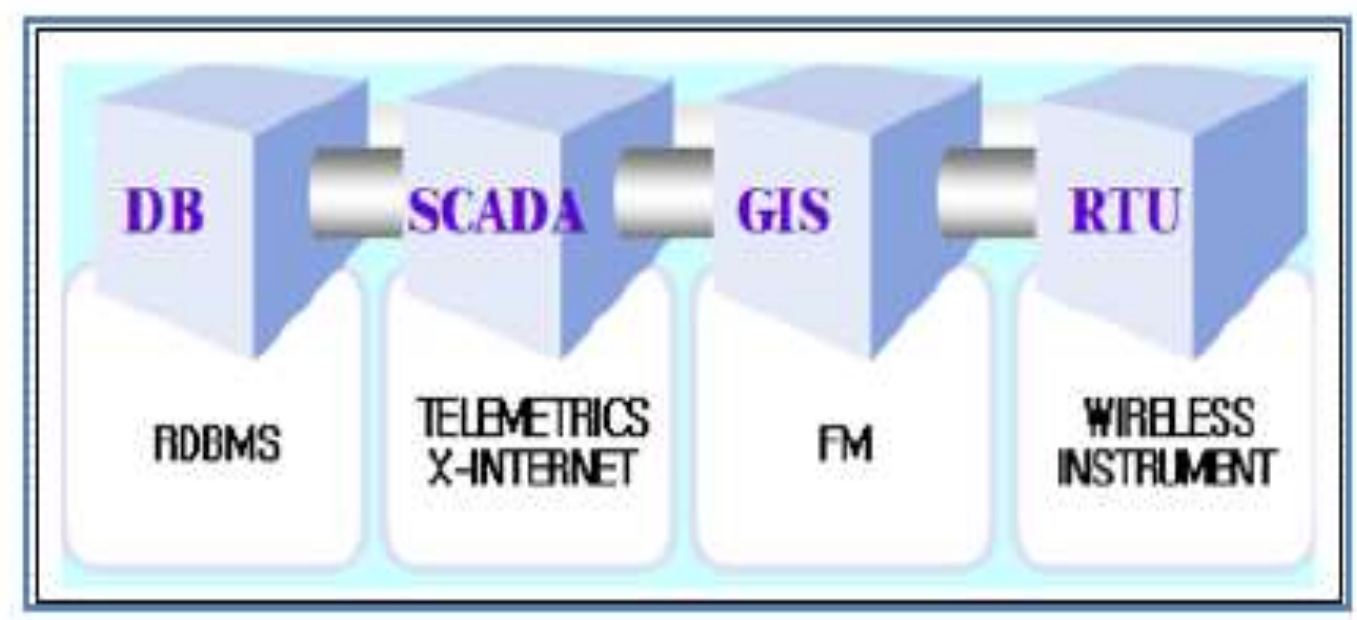

Fig. 4 Data Processing and Storage Computers and Peripherals 


\subsubsection{CHARACTERISTICS BY SENSOR TYPE}

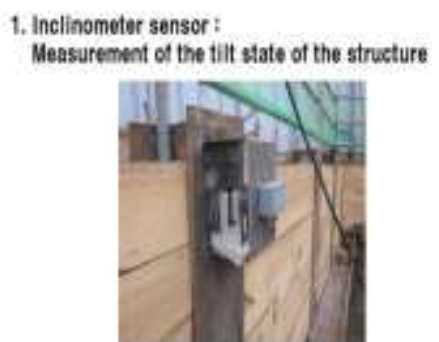

2. Strain Gauge Sensor :

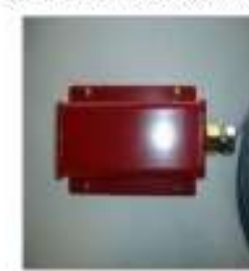

4. Displacement sensor: Measurement of displacement state of the structure

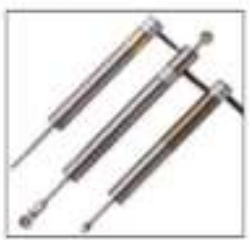

5. Water level sensor : Groundwater Level Messurement

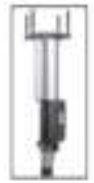

3. Load gsuge sensor:

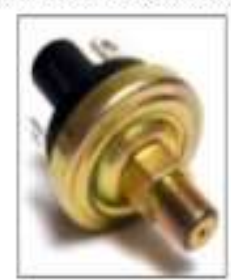

6. Acceleration sensor :

Measurement of vibration state of the structure

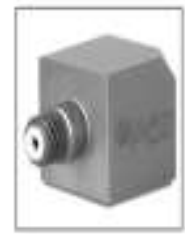

Fig. 5 Sensors that make up the wireless remote measurement management system

Types of sensors include inclinometer sensors, strain gauge sensors, load gauge sensors, displacement sensors, water level sensors, acceleration sensors, and rebar stress sensors and ground sediment sensors such as fig 5. Among them, the reinforcement stress gauge sensor is manufactured in the shape of the sensor housing about 20\% larger than the size of the deformed rebar, so that the yield point of the reinforcing bar can be measured [14]. In addition, it is mainly used to measure the stress acting on pile foundations because maintenance measurement is possible by automatic measurement and semi-permanent measurement, and the stress applied to reinforcement of reinforcement concrete structure or supporting retaining wall can be easily and precisely measured. This has the advantage that the stress change can be confirmed regardless of the construction progress of the superstructure.

Since ground sediment sensor does not expose sensor, it is possible to calculate accurate data because there are few hand trouble factors such as fig 6 . In addition, it is possible to maintain and measure by automated and semi-permanent measurement, and it is excellent in reproducibility and responsiveness because there is no influence on resistance change. Therefore, it is easy to select the measurement location according to the site conditions.
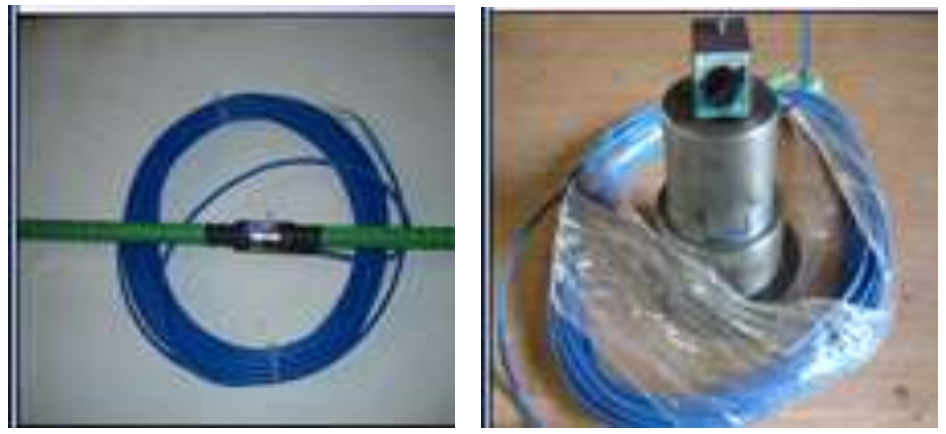

Fig. 6 Reinforcement stress gauge and Ground subsidence 
The wireless remote measurement device receives the sensor signal, converts it into measurement data, saves it as shown in Figure 4, then uses a wireless modem to send data to the remote server computer and receives control commands sent from the computer. An apparatus for performing a control function according to the present invention, which can be controlled by a program. Sensors and wireless telemetry devices inevitably contain actual structural behavior and critical errors due to the simplification of assumptions, idealizations, material properties, and analytical models during the structural design phase. Therefore, analysis and evaluation techniques based on measurement data are required. Based on this analysis and evaluation technology, you can build an alarm and maintenance system for each structural level [17]. The simplest way to compare the results of a measurement and determine its safety status is to make a judgment according to relevant standards.

If you do not have a relevant standard, you will need to consult the relevant technical data and relevant experts to set the criteria. In the operational management system, a monitoring program is developed to store the values measured by the sensors and allow the user to check in real time the measured data according to established criteria. The user can set the management value for each level required step by step, the program notifies the user step by step when it detects data exceeding the management value set by the user, and sends the text message to the mobile phone when the user is absent send. In order to inform the user of the status of the current structure, the most important safety assessment algorithms are developed and incorporated into the operational management system.

This study overcomes the limitations of existing automatic measurement technology, construction, cost and maintenance for structural safety management and significantly improves the reliability of measurement results, site construction and economy. This technology is a wireless remote safety management operating system that manages the safety status of temporary blocks in real time by connecting multiple sensors in serial and single lines to short and long distance wireless telemetry devices that integrate data logger functionality and communication.

\subsection{DEVELOPMENT OF NEAR-FIELD AND LONG-RANGE WIRELESS REMOTE MEASUREING DEVICE WITH INTEGRATED DATE LOGGER FUNCTION AND COMMUNICATION FUNCTION}

Conventional data processing methods use data loggers (wires using 18 or 36 channels as data processing devices) connected to sensors, management servers using portable data storage devices and wired and wireless communication devices. The data logger, communication device, and management server are configured as one device to send data to the system to verify the data.

As a result, the initial cost was high and uneconomical due to the need for a large amount of data processing units, power cables and management servers. First, the development technology simplifies system configuration by integrating data logger functionality and communication capabilities, as shown in Figure 8 and Figure 9. Second, the company plans to develop short-range wireless remote devices free of communication charges and free remote wireless remote devices [9]. Therefore, the configuration is ensured by the simplification of the system configuration, the system can be economically by rational placement of near and remote wireless remote devices.

4.3.1. LOCAL AND REMOTE WIRELESS TELEMETRY DEVICES: This development technology consists of 1) receiving a short-range wireless telemetry device with no communication cost at a relatively short distance (within $80 \mathrm{~m}$ ) of the measurement location in the field and 2) receiving data transmitted from the local area network. Long range wireless integrated device as shown in Figure 10. It is sent to a web server, so you can build an economical system without the need for cable layout. 
4.3.2. WHEN CONFIGURING AN NFC REMOTE MEASUREMENT DEVICE: If the distance between the measurement locations is relatively short, only one remote radio remote unit is installed, and the other consists of a near field radio telemetry unit such as fig 7 . This reduces communication costs.

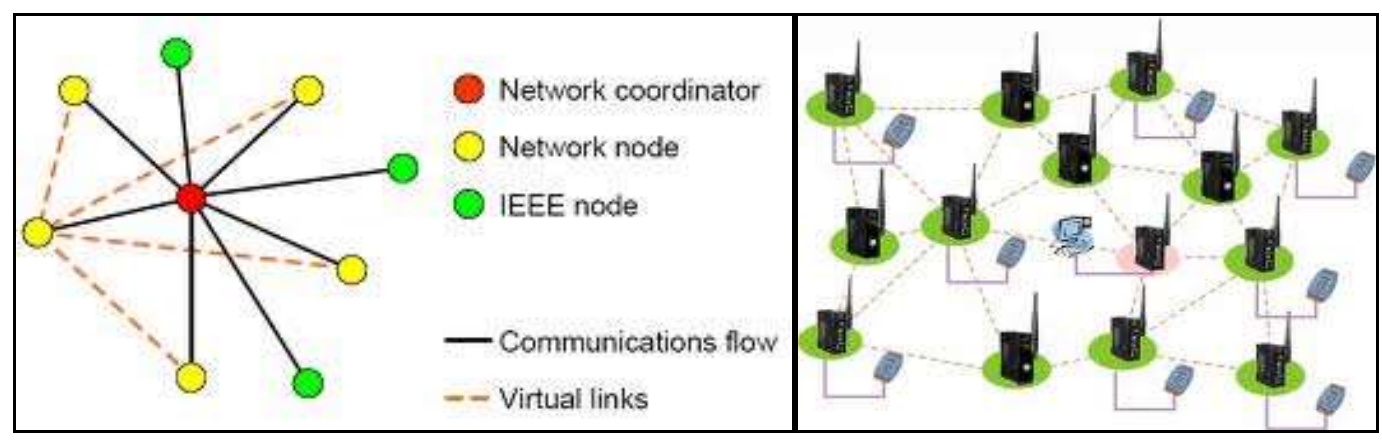

Fig.7 Network Diagram Using Sensor

4.3.3. WHEN CONFIGURING A REMOTE WIRELESS NETWORK: If the distance between the measurement locations is too long to establish a local area network, as shown in Figure 8-10, install a remote wireless remote device at each measurement location. No additional cable layout is required, which improves workability.

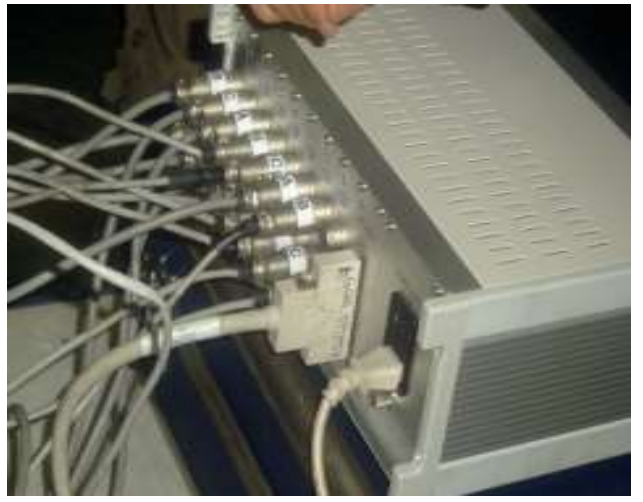

Fig. 8 Data logger connection

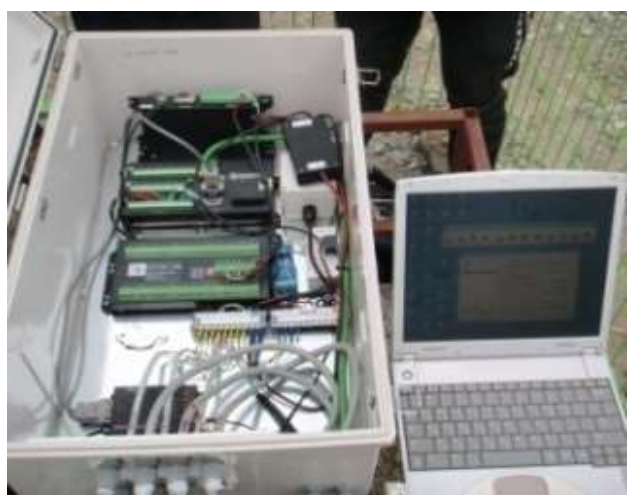

Fig. 9 computer connection

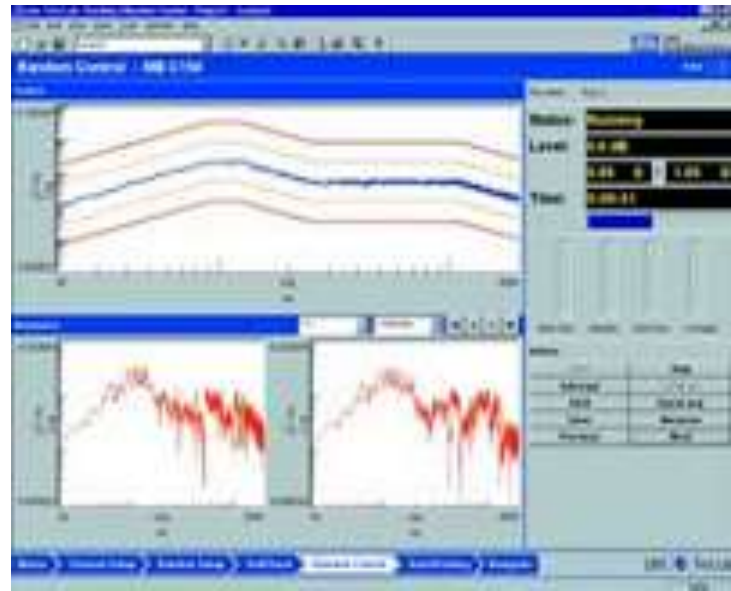

Fig. 10 Real-time remote measurement 


\subsection{CHARACTERISTICS OF THE REAL-TIME REMOTE SAFETY MANAGEMENT SYSTEM OF THE STRUCTURE}

Integrate data logger function and communication function to produce as one product, and can manufacture short distance wireless remote measuring device (communication fee free) and remote wireless remote measuring device separately.

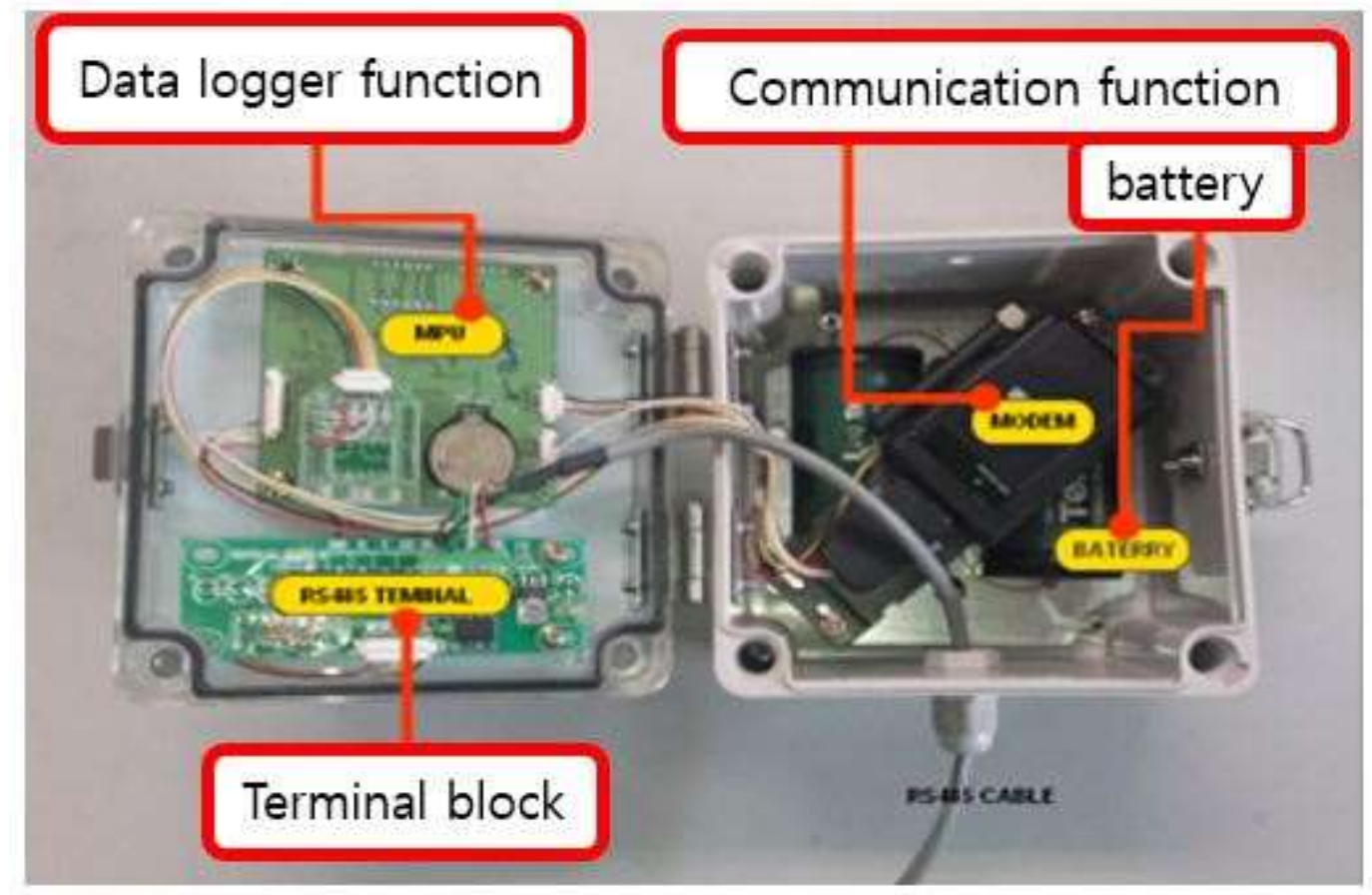

Fig. 11 Wireless remote measuring device

In the case of the existing automatic measurement, the data logger and the telecommunication device are separated into two parts. As shown in fig 11, the remote measurement technology data logger and communication functions of this study are combined to produce a single product. The short distance wireless remote measurement device and the remote wireless remote measurement device can be manufactured separately to reduce the communication cost with reasonable arrangement.

\section{TEST APPLICATION AND RESULT ANALYSIS OF DEVELOPMENT TECHNOLOGY}

\subsection{FIELD TEST INSTRUMENTATION}

In order to examine the quality performance of the technology of this study, a measurement device was installed at the construction site of a real structure and radio remote real-time measurement management was performed. For the comparative experiments, eight ground slope meters for manual measurement devices were installed, and two of them had inclinometer sensors for wireless remote measurement. For five months, manual and radio remote measurements were performed simultaneously in the $X$ direction (the trench direction) and the $\mathrm{Y}$ direction (the perpendicular direction of the trench). 


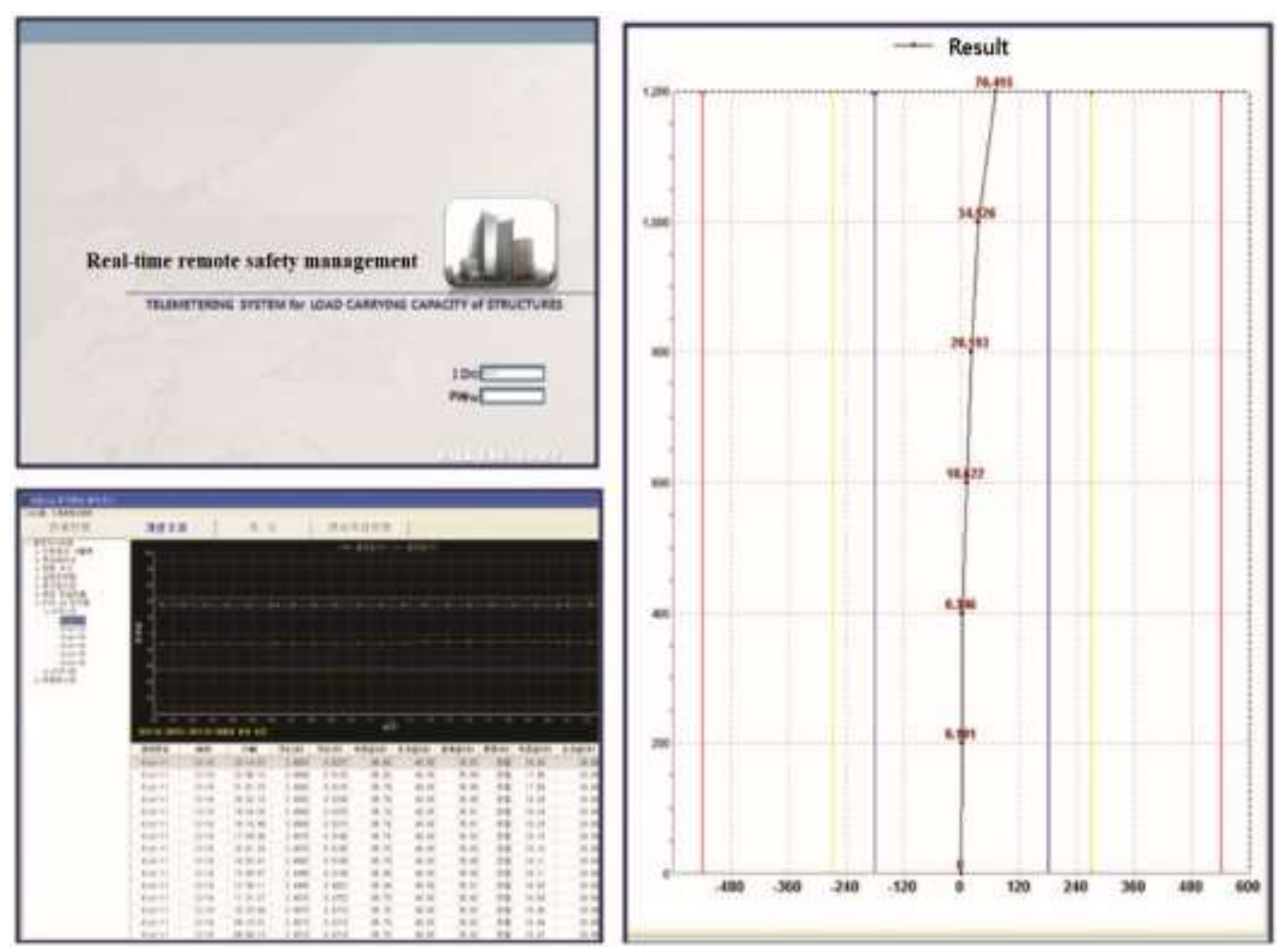

Fig. 12 Wireless remote real time measurement management program

Fig 12 shows the situation of monitoring the displacement of the structure using the measurement control system. The user can check the data transmitted automatically to the web server through the measurement management system according to the setting cycle. In addition, it is possible to determine the safety of the structure in real time using the automatic notification function for the sudden displacement.

\subsection{MEASUREMENT DATA ANALYSIS}

Table III shows the final maximum cumulative displacement of manual measurement and wireless remote measurement. The results of the two measurement methods showed errors of about $0.20 \mathrm{~mm} \sim 3.00 \mathrm{~mm}$. Figure 13 shows the trends of manual measurement results and radio remote measurement results during the construction of the wall.

Table III. Comparison of manual measurement and radio telemetry displacement

\begin{tabular}{|c|c|c|c|c|}
\hline \multirow{2}{*}{ direction } & \multicolumn{2}{|c|}{$\begin{array}{l}\text { Final measured value (maximum cumulative } \\
\text { displacement) }\end{array}$} & \multirow{2}{*}{$\begin{array}{l}\text { Management } \\
\text { standard } \\
(0.005 H)\end{array}$} & \multirow{2}{*}{ judgment } \\
\hline & $\begin{array}{c}\text { Manual } \\
\text { measurement }(\mathbf{m m})\end{array}$ & $\begin{array}{l}\text { Wireless remote } \\
\text { measurement }(\mathbf{m m})\end{array}$ & & \\
\hline NO-1, $\mathrm{X}$ direction & 73.44 & 70.47 & 60.00 & caution \\
\hline NO-1, Y direction & 2.20 & 2.00 & 60.00 & stability \\
\hline NO-2, $\mathrm{X}$ direction & 18.00 & 16.58 & 60.00 & stability \\
\hline NO-2, Y direction & 2.80 & 2.30 & 60.00 & Stability \\
\hline
\end{tabular}



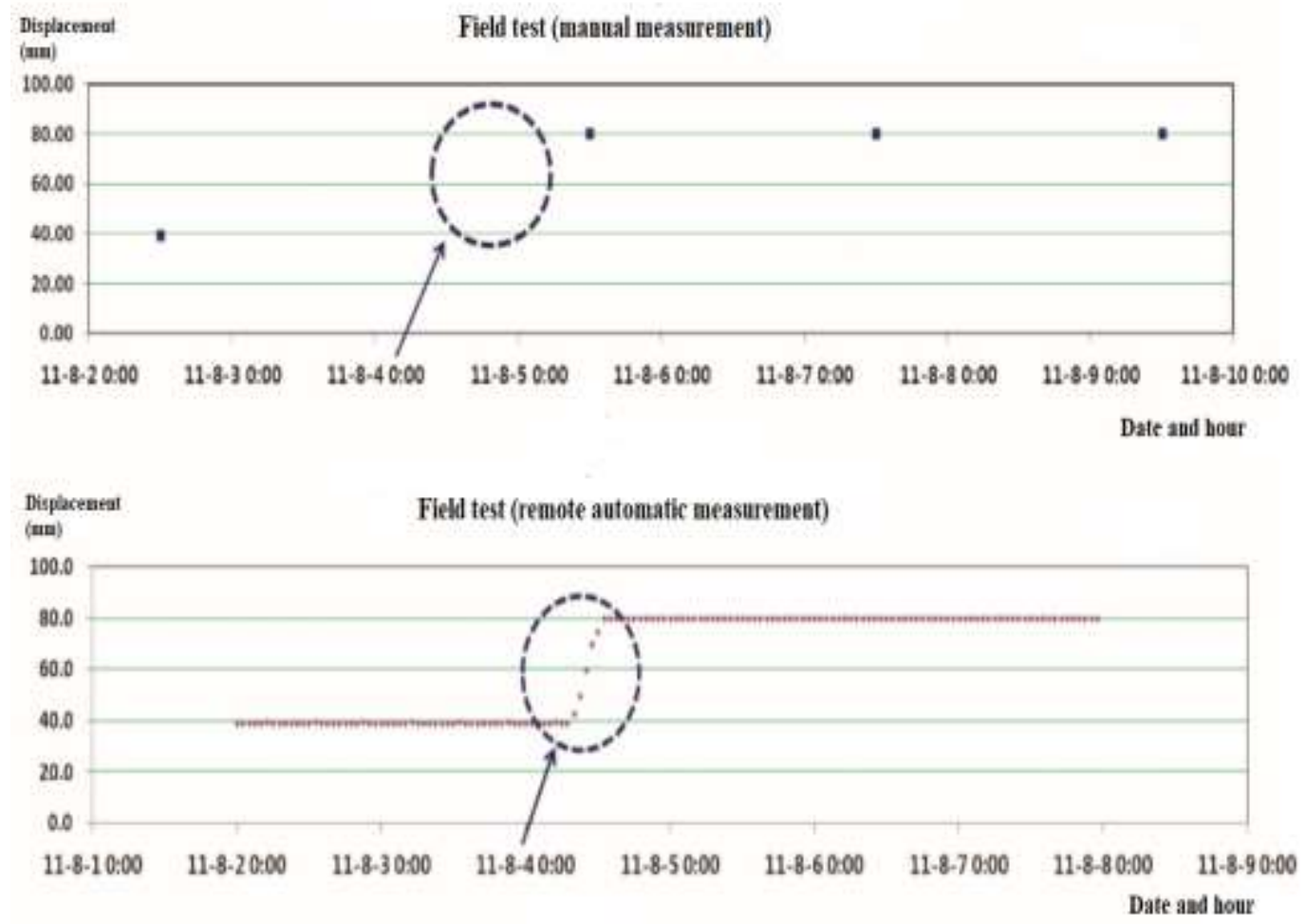

Fig. 13 Comparison of Passive and Wireless Remote Measurement Results

As a result of the field application of this technology, the measurement data could be easily obtained according to the measurement cycle set by the user in consideration of the site conditions and the required level of management. In addition, the wireless remote measurement was able to confirm the behavior of the earthquake block facility in real time by showing a continuous flow of data, and more systematic safety management was possible. Measurement management using this technology was carried out at about 10 sites, and data were collected reliably in all projects to perform smooth measurement management such as fig 13 .

\section{CONCLUSIONS}

Through this research, it is possible to establish a plan for improving the safety management of facilities. If it is possible to build a system for the system's permanent safety monitoring system, it will be possible to prevent large accidents, thus preventing the casualties caused by the deformation of the structure at home and abroad. The development technology can establish a regular safety monitoring system via wireless telemetry devices via the Internet after the construction of the structure is completed.

In addition, since the applicability of the existing measuring device improves the limitations on the convenience and ease of use, the application of construction structures can be extended together. The radio remote measurement technology of this study is efficient in terms of completeness, quality and constructability.

In addition, it is a technology that can always be safe management by real-time measurement of the displacement of various facilities and the surrounding ground, it is possible to efficiently manage the safety of the main structure. In the future, it will be developed into an integrated safety management system for safety monitoring and condition analysis of construction structures with various sensors. 


\section{REFERENCES}

[1] Kim Ja Yeon. "research on the actual condition and awareness degree of time shortening. " Korea Institute of Building Construction, 10 edition vol.5 (2010): 87-95

[2] Teng Ma, Yun Liu, Junsong Fu and Ya Jing, "A Reliable Information Fusion Algorithm for Reputation Based Wireless Sensor Networks", International Journal of Future Generation Communication and Networking, NADIA, ISSN: 2233-7857 (Print); 2207-9645 (Online), vol. 8, no. 1, February (2015), pp. 281-298.

[3] Zhen-Rui Peng, Hong Yin, Hai-Tang Dong, Hui Li and An Pan, "A Harmony Search Based Low-Delay and Low-Energy Wireless Sensor Network", International Journal of Future Generation Communication and Networking, NADIA, ISSN: 2233-7857 (Print); 2207-9645 (Online), vol. 8, no. 2, April (2015), pp. 21-32.

[4] Yang Zhongguo and Cai Tianfang, "Wireless Sensor Network Achieved by Automatic Positioning System Node", International Journal of Future Generation Communication and Networking, NADIA, ISSN: 2233-7857 (Print); 2207-9645 (Online), vol. 8, no. 2, April (2015), pp. 93-104,

[5] Popper, R., Keenan, M., Miles, I., Butten, M., and Fuenza, G. "Global Foresight Outlook 2007, EFMN " S27-7 (2009): 956

[6] Xiaoqing Yu, Wenting Han and Zenglin Zhang, "Overview of Transmission Characteristics in Novel Wireless Underground Sensor Networks", International Journal of Future Generation Communication and Networking, NADIA, ISSN: 2233-7857 (Print); 2207-9645 (Online), vol. 8, no. 2, April (2015), pp. 233-242, http://dx.doi.org/10.14257/ijfgen.2015.8.2.18.

[7] K.H.S Sabaragamu Koralalage, "Where the POP Architecture Stands among the other RFID Solutions was recalled by author because authors found some critical problems. ", International Journal of Security and Its Applications, NADIA, ISSN: 1738-9976 (Print); 2207-9629 (Online), vol.3, no.1, January (2009), pp. 65-76.

[8] Tianshu Wang, Gongxuan Zhang, Xichen Yang and Yang Lv, "The Cluster Head Preferred Hierarchical Clustering Routing Protocol Based on G-Means in Wireless Sensor Networks", International Journal of Future Generation Communication and Networking, NADIA, ISSN: 2233-7857 (Print); 2207-9645 (Online), vol. 8, no. 3, June (2015), pp. 179-190.

[9] Nourah A. Almubarak, Anwar Alshammeri, Imtiaz Ahmad, "Automata Processor Architecture and Applications: A Survey", International Journal of Grid and Distributed Computing, NADIA, ISSN: 2005-4262 (Print); 2207-6379 (Online), vol.9, no.3, April (2016), pp. 53-66.

[10] Yu, H.S, Korea Institute For Industrial Economics \& Trade Construction-IT Convergence Market, "Technology Trends and Policy Implications. " (2010)

[11] Jiang Hui-Lin, Qiao Li and Fu Yi-De, "Research on Query Gain Routing Algorithms and Load Balancing Mechanism in Wireless Sensor", International Journal of Future Generation Communication and Networking, NADIA, ISSN: 2233-7857 (Print); 2207-9645 (Online), vol. 8, no. 2, April (2015), pp. 307-316.

[12] Zeyu Sun, Yaping Li, Yangjie Cao, Yuanbo Li, "Evaluation Model Queuing Task Scheduling Based on Hybrid Architecture Cloud Systems", International Journal of Grid and Distributed Computing, NADIA, ISSN: 2005-4262 (Print); 2207-6379 (Online), vol.9, no.6, June (2016), pp. 169-180.

[13] Bea, Y.H., Korea Institute of Construction \& Transportation Technology Evaluation and Planning, "Development Performance Measurement for Construction Technology Research." (2009): 2-32. 1512

[14] Min Zhu, Dengyin Zhang, Zhanxiang Ye, Xuemei Wang and Jin Wang, "A Network Coding Based Routing Protocol in Wireless Sensor Networks", International Journal of Future Generation Communication and Networking, NADIA, ISSN: 2233-7857 (Print); 2207-9645 (Online), vol. 8, no. 2, April (2015), pp. 365-372.

[15] Jeon Hwang-su. "Trends in the development of Auto-IT convergence technology in Korea and abroad, Korea Multimedia Society. " Vol. 14 (2009).

[16] Korea Information Society Development Institute (KISDI). "The Direction of Next Generation IT Industry Policies and related Future Tasks" (Korean) (2007)

[17] Basim Abood, Yu Li, Nasseer Bacheche and Aliaa Hussien, "Biogeography-Based Optimization Algorithm for Prolonging Network Lifetime of Heterogeneous Wireless Sensor Networks", International Journal of Future Generation Communication and Networking, NADIA, ISSN: 2233-7857 (Print); 2207-9645 (Online), vol. 8, no. 2, April (2015), pp. 381-390. 
International Journal of Advanced Science and Technology Vol.135 (2020) 